\title{
Challenges of Processes Simulation with Dynamic Batch Processing Activities
}

\author{
Igor Pihir ${ }^{1, *}$, Katarina Tomičić-Pupek ${ }^{1}$ and Neven Vrček ${ }^{1}$ \\ ${ }^{1}$ Faculty of Organization and Informatics, University of Zagreb \\ Pavlinska 2, 42000 Varaždin, Croatia \\ E-mail: <\{ipihir, ktomicic,nvrcek\}@foi.hr>
}

\begin{abstract}
Business Process Management (BPM) often encompasses process improvements based on Information and Communication Technologies (ICT). Business processes simulation can be used as a tool for estimation of optimization parameters. Commercially available BPM tools in accordance with BPMN 2.0 support have built-in simulation features, which vary in the extent of support to advanced process simulation options. In this paper, we address dynamic batch processing activities as a challenge for BPM tools with simulation features and their dynamic impact on the executing activities. Further on, basic process scenarios examples were used to test and evaluate the capabilities of selected BPM tools, especially in relation to the Time Driven Activity Based Costing model (TD ABC model). The closing part of the paper deals with significant limitations of BPM tools in terms of supporting the batch processing activities, and the comparison with the TD ABC model simulation as a temporary solution to these problems. The main findings of this paper imply that contemporary BPM tools with BPMN 2.0 support still need to implement better options for handling simulation of dynamic batch processing activities.
\end{abstract}

Keywords: batch processing problems, batch activity, business process management tools, process simulation, TD ABC model

Received: February 8, 2018; accepted: March 28 2018; available online: July 24; 2018

DOI: 10.17535 /crorr.2018.0009

\section{Introduction}

Business Process Management aims to create and implement efficient, cost-effective business processes that are manageable and maintainable over time. Simulation of business processes, as part of the process modelling and improvement activities in BPM, plays a significant role in the assessment of the effects of ICT and optimization of resources.

Simulation modelling of business processes is useful for: a) analysis of process dynamics, b) prediction of the effects of change and c) experimentation on models [5]. Simulation can be defined as conducting of experiments in the computer-supported models [24]. Although simulation can be done in other ways (manually), the contemporary software and powerful computers make it easy and accessible. Many well-known tools for business process management provide support for simulation, such as: Software AG ARIS [26], IBM WebSphere Business Modeler [13], BizAgi Process Modeler [4] and iGrafx Process [15], [16]. 
Simulation as a tool for predicting future business outcomes is considered essential in the analysis of the business process improvement, especially when exploring the impact of ICT. Business process management/modelling tools (BPM tools) provide support for simulation as part of process analysis and optimization. Although these tools support simulation, with capabilities researched previously in Pihir, Žajdela-Hrustek, Dušak [22], there are challenges in their simulation capabilities that limit or obstruct their use in the processes that include activities with batch processing.

In this paper, a batch processing activity is considered as an activity in which the available resource can process more than one business item instance in one single execution of the activity. This means that some "single processing" activities are processing just one business item at a time in one activity execution, while "batch processing activities" process more than one business item (e.g. group of business items) in one activity execution. Business item can be defined, according to IBM Knowledge Center [14] as "a business document, work product, or commodity that is used in business operations. Examples of business items are a manufacturing order, motherboard, power supply, and memory chip (in a PC assembly process), itinerary and customer information record (in a trip reservation process), and passenger (in a transportation process)".

Batch processing and dynamic aspects of change in the capacity of an activity over time become a serious issue when running simulations of complex process models, especially in the process models with several hierarchical levels (sub-processes).

Due to the importance of simulation features of BPM tools, authors explored the dynamic aspects of the simulation, specifically in the activities with batch processing within the process model. This research also explores the possibilities of some popular business process modelling and management tools, such as IBM WebSphere Business Modeler v 7.0.0.4.1 [13]; [22] and BizAgi Modeler v 3.1 [4]. Simulation of batch processing activities is further researched through the use of the Time Driven Activity Based Method model (TD ABC model) [17]; [21] that can help simulate such processes in a simpler manner. Limitations of both approaches were compared, possibilities in contemporary BPM tools in process simulation were assessed, and advantages and disadvantages in comparison to the TD ABC model simulation were described.

\section{Problem definition}

Software AG ARIS Community BPM Glossary defines business process simulation as instrument "for the analysis of business processes. It is used to assess the dynamic behaviour of processes over time, i.e. the development of process and resource performance in reaction to changes or fluctuations of certain environment or system parameters. The results provide insights supporting decisions in process design or resource provision with the goal to improve factors such as process performance, process and product quality, customer satisfaction or resource utilization" [3]. Simulation as a method of assessing process behaviour over time is recommended by many authors and is used commonly in the process improvement justification e.g. Bosilj Vukšić et al. [5], Hoyer [12]. It is part of the process management life cycle in the design and analysis of many BPM tools [27].

Simulation is often used as a support for decision making, both on operational and strategic level management in complex systems [29], or for prediction of future states in business process reengineering [11] and business process improvement projects [30] to evaluate and compare 
current and future state of business processes. It has been in the focus of research activities of many practitioners and academics [19].

Software support for complex simulation models is often limited. Van der Aalst [1] describes 15 risks and potential pitfalls in simulation and the batch processing is one of them. Feraitas and Pereira [7] did a general review of BPM tools, based on their simulation properties and they expect the implementation of simulation to become a standard feature in BPM tools. Ranking of business process simulation software tools was done by Damij et al [6], as a methodological approach to the selection of appropriate simulation tool for business process simulation.

This paper aims to explore batch processing simulation constraints in some BPM tools in the specific types of activities (batch activities) that often occur in business processes. Silver [25] states that batch processing common use-case is where one part of the process operates on "batches" of items that are processed one at a time in another part of the process.

Batch processing activities could be described as grouped instance running activities. They are characterized by their ability to execute once while processing more than one business item instance at the same time. In the simulation jargon, task capacity is defined by processing more than one input and/or more than one output at the same time of the activity execution. This means that batch activity processes more than one simulation token at the same time.

Batch processing is traditionally related to computer processing as "the executions of a series of programs (jobs) on a computer without manual intervention", Wikipedia [28]. In this paper, we consider a batch processing activity as an activity in which the available resource can process more than one business item instance in one single execution of the activity. The typical batch activity costs are: set-up costs in machine preparation, costs of moving materials or loading machines. In this manner, the costs of batch activity would be assigned to all products made by machine in the same batch (series).

The problems of batch processing within an individual activity in the simulation of processes were investigated by Pufahl and Weske [23] and Liu and $\mathrm{Hu}$ [18]. They found that batch processing activities in simulation tools lack support, and recognized batch activity as a particular type of activity in the process, especially if its dynamic capacity is changing over time. To overcome such problems, Alexander [2] used discrete simulation for batch processing and simulated complex process groups of tasks or activities, needed to be executed together, as a single processing activity with simulation of business items that presented a group of business items. Simulation options were implemented into the process simulator iGrafx, but such simulation is suitable only if we simulate groups of tasks done together and if the capacity of the group (batch) does not change during the process and/or over time.

Van der Aalst [1] further states that people like to work in batches and tend to let work-items related to the same task accumulate (i.e. people tend to create a group of business items by collecting them), and then process all of those in one batch.

Batch activities do not represent parallel execution of business item instances in activities; rather, they simply represent the processing of business items instances as a group i.e. in one run. Examples of batch processing can be found in the most common business processes. Sometimes when a process is modelled on a higher level, this kind of activities and intermediate steps in a process could be neglected or simplified.

Below are some other examples of the batch processing activities:

a) Activities in which more business item instances are moved from one processing location to another, e.g. invoices are created individually, one at the time, and then 
they are mailed all together to another place, for signing as a group of instances (see Figure 1).

b) Activities in delivery processes, where one truck is loaded for delivery of the goods ordered by more than one order, loading one order of goods at the time, and then all goods (from all orders) are transported to a common location.

c) Activities in booking processes, where tickets on charter flight, on which a company allows passengers to book $\mathrm{N}$ seats, are booked one seat at the time, and in the case of e.g. ten or more passengers' reservations, the airline company confirms reservations and informs (by e-mail, SMS) all passengers at once, and only if the flight has been sold out to a certain pay-out percentage, that the flight is confirmed.

Specifically, batch processing cannot be simulated if the business items are processed dynamically and the number of items changes over time e.g. the size of the plane booked in (c), the capacity of truck relative to the individual order size in (b) or the number of invoices in a day (a).

In most simulation tools, the batch processing activities (as shown in previous examples) become problematic due to the number of business item instances to be processed in the batch. The variability of business item instances and the complexity of process models are in most cases difficult to monitor and control. The following chapters deal with the methodology and research on how to overcome these identified problems.

\section{Methodology and research design}

In order to investigate possible solutions to the problems of simulating and handling multiple instances in the batch processing activities, a research scenario was developed. It is based on the previously identified problem, feasible techniques found in the literature reviews, and the authors' practical and research experience.

The research scenario includes the following:

1) Development of an exemplary process model, describing challenges of the batch processing activities in a single general process model - Big Picture approach (Figure 1)

2) Development of four testing case process models (A, B, C and D) with batch processing activities (Figures $3-6$ in chapter 4 )

3) Conducting of simulation experiments in selected tools for all cases.

4) Comparison of simulation results and assessment of simulation capabilities for batch processing activities support.

In order to conduct simulation experiments, the following was performed:

a) Selection of business process modeling tools

b) Investigation into and determination of comparison criteria for batch processing simulation capabilities.

\subsection{Selection process for BPM tools}

To address the simulation issue, two among the business process modeling tools were selected for this research. The tools were selected on the basis of:

1) Several years of authors' experience in various BPM projects, after analysing more than 100 process models in various organizations. 
2) Gartner reports on BPM tools.

These criteria were applied to select two BPM tools. The first selected tool was the IBM WebSphere Business Modeler in its advanced version 7.0.0.4.1 [13]. According to the latest Gartner Magic Quadrant of iBPMS tools from August 2016 [10] and March 2014 [9], IBM is the leading vendor of the contemporary business process management tools, also called iBPMS (Intelligent Business Process Management Suits).

In addition, the previous Gartner's analysis from 2010 [8] ranked IBM as one of the leading vendors of BPA tools (Business Process Analysis Tools), together with the second tool we used in our analysis, which the BizAgi Modeler marked as visionary [8].

The second used tool. BizAgi, also a very contemporary process modeler, has stepped from visionary to challenger quadrant in Gartner 2016 report "Magic Quadrant for Intelligent Business Process Management Suites" [10] due to easy use and friendly environment provided by full BPMN 2.0 support. Both of these tools support simulation and BPMN 2.0 notation as one of the leading standards in the business process modelling [20].

\subsection{Comparison criteria for batch processing simulation capabilities}

To evaluate the capabilities of selected BPM tools, the following criteria were selected:

1) Capability of supporting testing cases (A-D)

2) Common simulation capabilities related to the average processing time and resource utilization

3) Additional simulation capabilities related to detailed process properties, such as waiting times, resource micro utilization, average process costs, etc..

This specific set of criteria for comparing the dynamic possibilities of the BPM tools were selected on the basis of the prior literature review and authors' experience with the larger set of simulation tools on several projects.

\section{Results - challenging batch processing activities in the selected simulation tools}

Simulation examples were provided by the IBM WebSphere Business Process Modeler Advance version 7.0.0.4.1 [13], in the BizAgi Process Modeler version 3.1 [4]. Figures 1-7 present process models and simulation results in both tools, but the images are based on the BizAgi Process Modeler graphic and they all present the results made in both tools. The interval used as an example is always one unit of time (irrelevant for this analysis).

The example in Figure 1 shows the basic challenge of simulating a process with batch processing activities. After the names of activities, number of business item instances execution are given in brackets, denoting the number of business item instances processed simultaneously (1 denotes only one while $\mathrm{N}$ denotes a batch).

Figure 1 presents the subprocess, which creates an invoice for goods or services sold earlier (in another subprocess). The invoices can then further be processed in two separate ways: in a paper format (AS IS) or as an electronic invoice (TO BE). The processing within the activities is done individually i.e. "single processing activity" (invoice per invoice) as the label in the activity name is indicated with tag "(1)". In addition, in other activities, invoices are first grouped in a batch and then processed together i.e. the "batch processing activity", as indicated by designating the activity whose name ends with tag " $(\mathrm{N})$ ". 


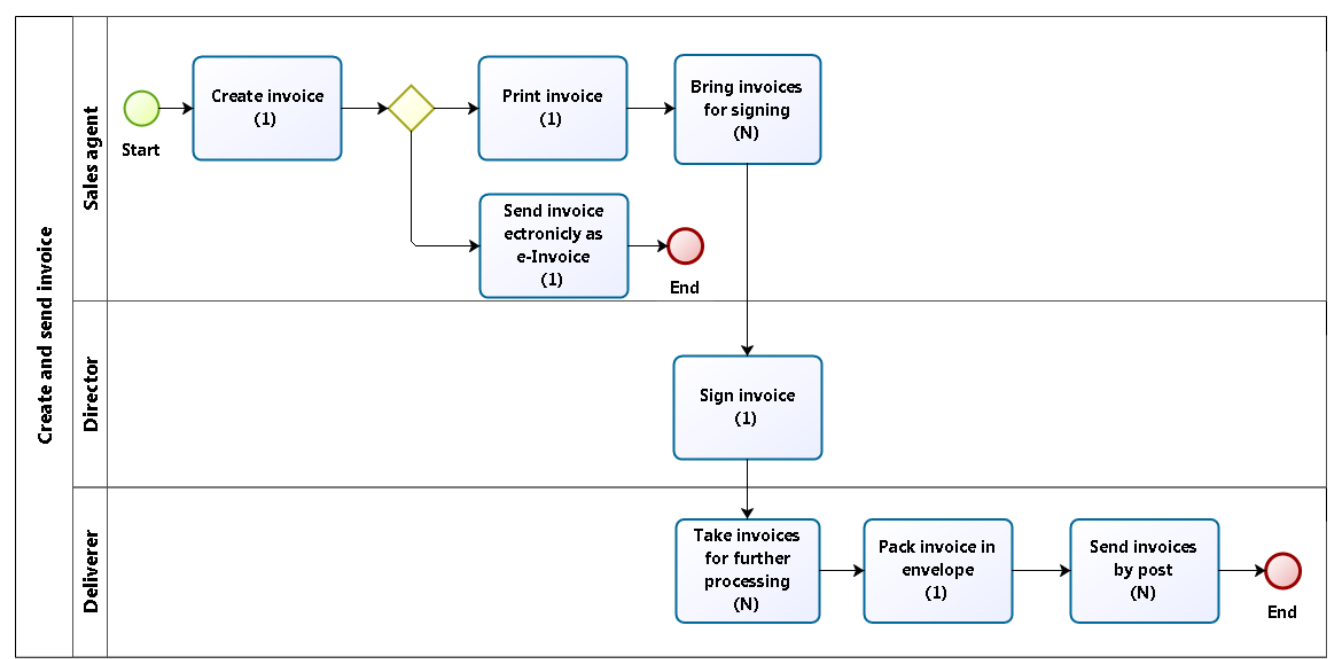

Figure 1: Process of creating and sending invoices in paper (AS IS) or electronic form ( $T O B E$ )

This process example demonstrates how processes with several batch activities and a variable amount of invoices to be processed in a group (due to dynamic exclusive decision gateway after the first activity), are challenging for simulating. When the process is dynamically executed in a given time e.g. during working days in a month (every day a different number of invoices are created, signed and then sent by post or by way of electronic invoice) then the batch processing activities are difficult to simulate due to the fact that only a fixed number of instances per time unit can be assigned as an input in the simulation properties.

The situation with batch processing activities in the process model and the way of supporting this kind of activities in simulation engines is presented in the next four case study examples (Case A, B, C and D).

\subsection{Research of case studies}

In both selected BPM tools, we tested the multiple simulation with Cases A, B and C, together with the situation described in Figure 1 and Figure 6 (Case D). The results of the simulation and the subsequent analysis showed certain shortcomings in supporting complex process simulation (e.g. Case C), especially if the dynamic capacity changes are involved.

Figure 2 shows basic numerical properties important for understanding of the simulation issues. The cases shown in Figures 3-5 show sets of activities demonstrating step by step what is happening in certain types of simulation experiments.

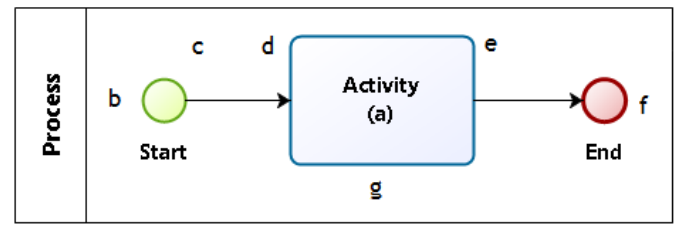

Figure 2: Description of example process model and additional information

In Figure 2, letter "a" refers to the number of item instances processed in an activity (single or batch processing) in a single run. Letter " $b$ " refers to the number of simulation tokens (process 
iteration in simulation experiment) which can be set as simulation property in most BPM tools. At the exit of the start event, letter "c" represents the number of items (tokens) per bundle in one process start; thus showing an initial batch. Letter "d" stands for the number of input business items (tokens) that is needed to start the next activity e.g. the activity needs only one input to start " 1 " or if $d=10$ then activity starts only if 10 business items are waiting Similarly, letter "e" stands for the number of output items (tokens) generated at the end of the activity execution. At the end event of the process, model letter "f" represents the number of item instances (tokens) processed in the simulation experiment altogether. This needs to be the same as "b" number of tokens at the start of the process simulation experiment. If a process model has more than one end event, then the sum of all tokens at the end of all process paths must equal "b". Letter "g" stands for the number of times the activity was run in the simulation experiment.

The following real-life simplified cases shown in Figures 3, 4 and 5 demonstrate several possible scenarios of simulation capabilities in process models (as mentioned in chapter 3.1.). It will be shown how to interpret various scenarios and the difficulty of handling "N" or unknown number of tokens that can be changed every time an activity runs, depending on the number of items in a bundle at the start of the process.

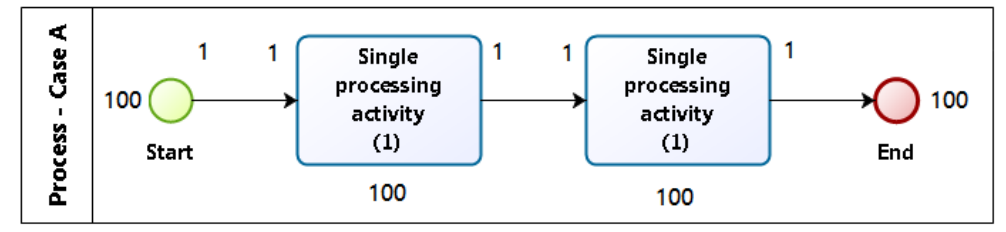

Figure 3: Example of a process without batch processing activities - Case A

Case A (Figure 3) is a simple process where one item instance is processed per activity execution (execution of items one at the time), which is most common when activities in the process have a capacity of one input/output business item instance (token) per process execution e.g. one order or one invoice. In our simulation experiment, the process was simulated with 100 tokens that started the process execution one at a time at defined intervals. They were all processed at the end of the process execution. Each activity was run 100 times.

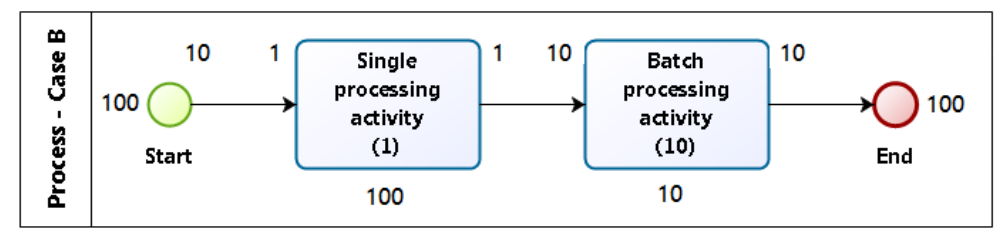

Figure 4: Example of a process with single and batch processing activities - Case B

Case B (Figure 4) represents a process in which we had one single processing activity followed by the second activity with batch processing that executes only when fixed number of input items (tokens) are available (in this case 10 items). In our simulation experiment, the process execution starts by generating 10 items per day (items are generated as a bundle, in groups of ten per day). Then they are processed one at a time in the first single processing activity. The second activity, however, runs only ten times. At the 
end, all hundred items (tokens) are processed. This case is the most commonly supported batch processing activity behaviour in BPM tools.

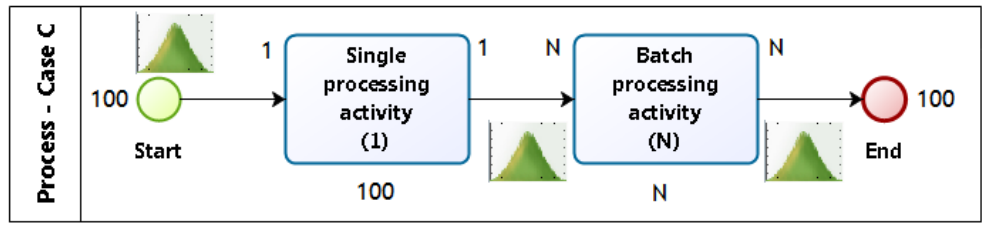

Figure 5: Example of a process with stochastic batch processing capacity - Case C

Case C (Figure 5) represents a complex process behaviour in which the first single processing activity runs every time a single item instance (token) is processed. The second activity is a batch processing activity, which runs depending on the number of input items (tokens). The number of instances needed to run the second activity depends thereby on probability distribution of the number of business items generated at the start of the process. In each running of the simulation experiment, the process starts with a different number of items, which depends on the input simulation distribution. Every day, the process can be started with a different number of items to be processed that day. This example can also be seen as an example of stochastic process start, which is different each time the process runs. The tokens are "coming" to simulation model in groups (bundles). In the simulation experiment, the simulation results will show the execution of the first activity hundred times, and random (N) times in the execution of the second activity. A typical such process is the number of invoices created and delivered per day.

Case $\mathrm{C}$ is a process model with complex simulation input parameters at the start of the process and changing batch processing characteristics during the execution. This scenario would in most process simulators result in a simulation error. As seen in Figures 1 and 3-5, there are various possible scenarios of batch processing in a single process model, depending on the probability distribution of possible input and output capacity of the activities, forming thereby complex models with challenging simulation properties. When Case C (Figure 5) or Case B (Figure 4) is implemented in process models, the simplified process of invoice creation (Fig. 1) is presented in Figure 6.

When the "capacity" of the batch processing activity is fixed (Case B) or dynamically changed over time (Case C), then the simulation errors occur in the processes that have gateways which form more than one path for the process execution. In those examples, the tokens from the start of the process are split at the process branching points and the number of tokens coming as input into the batch processing activity is smaller than predicted in the fixed input/output scenario (Case B), or in the dynamic scenario (Case C).

Thus, if the dynamic, the so-called "1:N" input capacity, is not run in the expected manner, than the simulation experiment shows results with errors. The dynamic capacity 1:N enables the activity execution to start when the activity input is at least 1 business item instance or more $(\mathrm{N})$, depending on the capacity over time, or on other behavioural characteristics of the process (like the number of items processed on a particular day e.g. number of invoices that will be sent by post on a particular day of the month). 


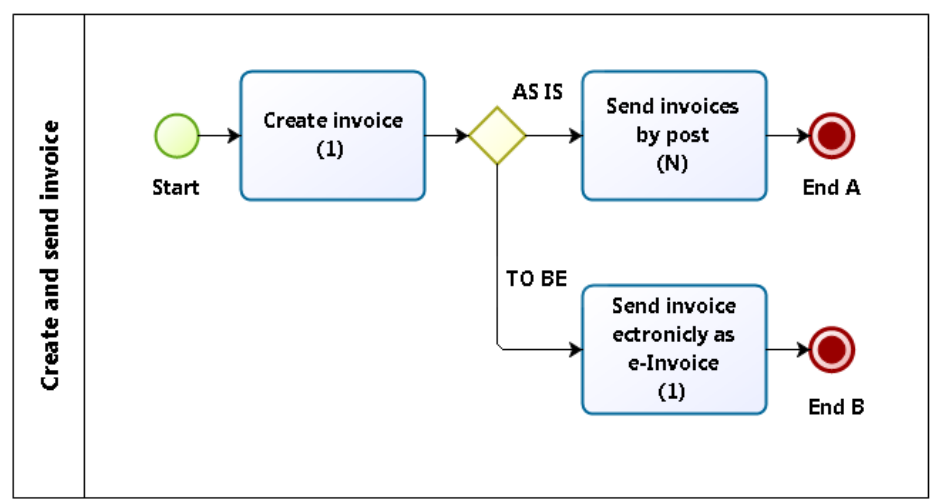

Figure 6: Example of invoicing process with two process paths - Case D

The examples presented in Figures 4, 5 and 6 show that the main problem in process simulators is the passage of item instances between the single and the batch processing activity. Most simulators allow this passage by enabling the fixed number of business items (tokens) to be processed at the same time (e.g. minimum input into activity is 10 and maximum input is 10 , as in Case B resulting with output of 10). This solution is working well if some control over that capacity of batch execution exists. For example, as shown in Figure 6, if we have an exclusive branching gateway and tokens are normally coming from branch AS IS, processed by fixed capacity in activity "Send invoices by post" every time, than the number of items needed is available (e.g. 10) and the process simulation will be run correctly. However, when the TO BE path is executed, than the execution of AS IS path in batch processing activity is not done at all, because there would be not enough items available on the input. On the other hand, the TO BE invoices are sent electronically, one at the time. These problems with batch processing activity mechanisms can be the main cause of failure of process simulation.

A detailed analysis of BPM tools solutions to this kind of batch processing activity and the process simulation are described in chapter 3.5. Also, as another approach for dealing with this issue is TD ABC (Time Driven Activity Base Costing) method [17], witch could be used as a supplementary solution for this kind of problems in the complex process simulation. The usable cost assessment, the proof of the concept of implementing the TD ABC method, and the comparison to older $\mathrm{ABC}$ method, are described and demonstrated in Peacock and Tanniru [21]. According to them, the TD ABC method is useful in simulation of IT investments feasibility and assessment of the business process improvement effects.

\subsection{Implementation of $\mathrm{TD} A B C$ method in process simulation}

As suggested in earlier chapters, common problems of batch processing activity simulation in BPM tools can be solved with the TD ABC model. The TD ABC method allows users to develop time equations based on the process model. Although TD ABC was developed for calculation and assessment of indirect costs of generating company's products and allocation of overhead labour cost of particular products and services, it can be used efficiently in assessment of process costs and resource utilization in complex business process models.

The implementation of the TD ABC method in calculation of the process model costs and in particular, in the processes with batch processing activities is demonstrated in Figure 6. If we 
modify the process properties and add duration to activities as well as costs of labour resources assigned to those activities, we can produce a simulation model based on time equations. This type of TD ABC model enables calculation of process' duration and direct cost of resources in few simple steps.

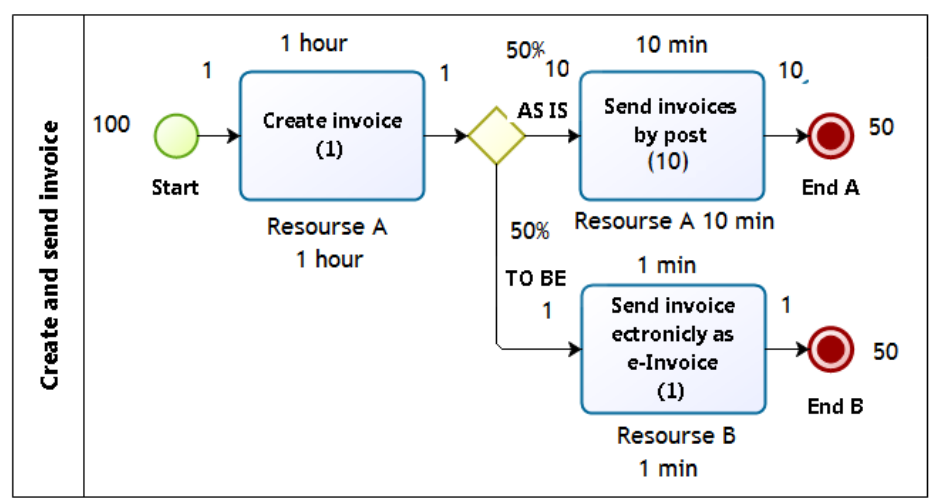

Figure 7: Example of invoicing process (Case D) with two process paths - TD ABC

Figure 7 shows the process of creating and sending invoices. It contains additional properties assigned to activities, which are shown at the top of every activity (activity's duration in one execution). The resource and the time needed to execute particular activity are presented at the bottom. In addition, in the middle of the process branching gateway the percentage of process path selection is shown (which is equally assigned to $50 \%$ for path AS IS and $50 \%$ for path TO BE). Simulation with 100 tokens needs to end with 50 tokens in the end event A and 50 tokens in the end event B.

To simulate this process model using the TD ABC method, it is necessary to develop time equation, which is defined as follows:

1) First, at the process start, the duration of the first activity is one hour so equation is one hour (60 minutes) multiplied by costs of Resource A (60 x Resource A).

2) Second activity in the process takes 10 minutes, so the equation is (10 x Resource $\mathrm{A})$.

3) Third activity takes one minute (1 x Resource B)

4) In general, all activities are "single processing" except for the second activity, which is "batch processing activity" with execution properties set with 10 tokens (as group) at one time.

5) At the end, it is necessary to merge all equations in one and to set the final number of simulation tokens that must be included (number of times to repeat the process e.g. in one year, month or week). In our example, it is 100 tokens. By simulating the processing of 100 invoices in one week, this means five times sending 10 invoices at the same time by post (AS IS) and 50 times sending single invoices (one by one) as an einvoice. The merging of partial equations results in one single equation:

(100 tokens $x$ (60 minutes $x$ Resource A)) + ((100 tokens x 50/100) / 10 items capacity) $x$ $(10$ minutes $x$ Resource $A))+(50$ tokens $x(1$ minute $x$ Resource $B))$

which results in: 
(6000 minutes of Resource $A)+(50$ minutes of Resource $A$ in second activity $)+$

(50 minutes of Resource $B$ in third activity)

Total process duration is: 6,100 minutes.

If the total of 6,100 minutes of the entire process duration is divided by 100 tokens in the process simulation, that gives an average processing time of 61 minutes per one invoice. Thereby, the resource utilization is in average 60.5 minutes of Resource $\mathrm{A}$ and only 0.5 minutes of Resource B per processing of one invoice. If we allocate the hourly rate to Resource A and B, we have direct cost of labour in our process example.

Similar models are easy to implement in spreadsheet calculators like Microsoft Excel, meaning that this approach could be used for complex simulation of business processes as well. Usage of such TD ABC model can help simulate complex processes with batch processing but it also has some drawbacks. These tools are capable of calculating only if activity running times are fixed. Mainly, this means that TD ABC model can provide, as seen in Figure 7, the average process cycle time per execution (time per one invoice in Figure 7). This is useful and easy to calculate even in complex processes. A disadvantage of this approach is that in this way it would not be possible to calculate other process parameters, like: time between two executions, executions delays due to resource time off (weekend, non-working time, overhead), simple micro resource utilization (per day or week, month), resource waiting times and other process parameters that are available in standard simulation tools.

To compare contemporary BPM tools capabilities in the process simulation of batch processing activities, IBM, BizAgi and TD ABC model were compared through all Cases in example process models: Case A, B and C together with Figures 6 and 7 (Case D).

\begin{tabular}{|l|c|c|c|}
\hline $\begin{array}{l}\text { Simulation } \\
\text { capability }\end{array}$ & $\begin{array}{c}\text { IBM WebSphere } \\
\text { BPM }\end{array}$ & BizAgi Modeler & TD ABC model \\
\hline $\begin{array}{l}\text { Capability of supporting testing cases and simulation capabilities of batch } \\
\text { processing activity }\end{array}$ & $\begin{array}{c}\text { supported } \\
\text { (no batch } \\
\text { processing activity) }\end{array}$ & $\begin{array}{c}\text { supported } \\
\text { (results useful) }\end{array}$ & $\begin{array}{c}\text { Supported } \\
\text { (results useful) }\end{array}$ \\
\hline $\begin{array}{l}\text { Case B - Figure 4 } 4 \text { - Figure } 3 \\
\text { (batch activity } \\
\text { with fixed capacity) }\end{array}$ & $\begin{array}{c}\text { supported partially } \\
\text { (results useful if } \\
\text { process has single path } \\
\text { and capacity is fixed) }\end{array}$ & $\begin{array}{c}\text { supported partially } \\
\text { (wrong batch } \\
\text { processing activity is } \\
\text { activated 100 times!) }\end{array}$ & $\begin{array}{c}\text { Supported } \\
\text { (results useful) }\end{array}$ \\
\hline $\begin{array}{l}\text { Case C - Figure 5 } \\
\text { (batch activity } \\
\text { with stochastic } \\
\text { capacity) }\end{array}$ & $\begin{array}{c}\text { supported as option } \\
\text { (results are confusing } \\
\text { and contain errors due } \\
\text { to mismatch of input } \\
\text { probability distribution } \\
\text { which is not linked to } \\
\text { stochastic capacity of } \\
\text { activity) }\end{array}$ & $\begin{array}{c}\text { not supported } \\
\text { (capacity definition } \\
\text { as fixed and not } \\
\text { working, before } \\
\text { version August 2014 } \\
\text { fixed capacity not } \\
\text { supported at all.) }\end{array}$ & not supported \\
\hline
\end{tabular}




\begin{tabular}{|c|c|c|c|}
\hline $\begin{array}{l}\text { Example of } \\
\text { invoicing process } \\
\text { with two process } \\
\text { paths - Figure } 6 \\
\text { and } 7\end{array}$ & $\begin{array}{l}\text { supported as option } \\
\text { but in case of second } \\
\text { activity type Case B or } \\
\text { C not working } \\
\text { because of branching }\end{array}$ & $\begin{array}{l}\text { supported for } \\
\text { activity type Case B } \\
\text { but not working }\end{array}$ & $\begin{array}{l}\text { supported for } \\
\text { activity type Case B } \\
\text { but in Case C not } \\
\text { supported }\end{array}$ \\
\hline $\begin{array}{l}\text { Common } \\
\text { simulation } \\
\text { capabilities }\end{array}$ & $\begin{array}{c}\text { IBM WebSphere } \\
\text { BPM }\end{array}$ & BizAgi Modeler & TD ABC model \\
\hline $\begin{array}{l}\text { Average processing } \\
\text { time (process cycle } \\
\text { time) }\end{array}$ & $\begin{array}{c}\text { supported } \\
\text { Case A, B (useful) } \\
\text { Case C, D (not } \\
\text { working) }\end{array}$ & $\begin{array}{c}\text { supported } \\
\text { Case A (useful) } \\
\text { Case B, C, D (not } \\
\text { working) }\end{array}$ & $\begin{array}{c}\text { supported } \\
\text { Case A, B and D } \\
\text { (with fixed capacity } \\
\text { useful), Case C } \\
\text { (useful if } \\
\text { distribution in } \\
\text { stochastic activity is } \\
\text { changed to fixed } \\
\text { average capacity) }\end{array}$ \\
\hline $\begin{array}{l}\text { Average time of } \\
\text { resource utilization } \\
\text { / per resource }\end{array}$ & supported & supported & supported \\
\hline $\begin{array}{l}\text { Additional } \\
\text { simulation } \\
\text { capabilities } \\
\end{array}$ & $\begin{array}{c}\text { IBM WebSphere } \\
\text { BPM }\end{array}$ & BizAgi Modeler & TD ABC model \\
\hline $\begin{array}{l}\text { Waiting (delay } \\
\text { times) }\end{array}$ & supported & supported & not supported \\
\hline $\begin{array}{l}\text { Resource micro } \\
\text { utilization (day, } \\
\text { week, month) }\end{array}$ & supported & not supported & not supported \\
\hline $\begin{array}{l}\text { Average process } \\
\text { costs }\end{array}$ & supported & supported & supported \\
\hline $\begin{array}{l}\text { Average process } \\
\text { costs / per resource }\end{array}$ & supported & supported & supported \\
\hline Calendars & supported & supported & not supported \\
\hline $\begin{array}{l}\text { Control of } \\
\text { input/output at } \\
\text { activity level }\end{array}$ & $\begin{array}{c}\text { fixed supported } \\
\text { (working), stochastic } \\
\text { supported (not } \\
\text { working) } \\
\end{array}$ & $\begin{array}{c}\text { fixed supported } \\
\text { (working), stochastic } \\
\text { not supported }\end{array}$ & $\begin{array}{c}\text { fixed supported } \\
\text { (working), stochastic } \\
\text { not supported }\end{array}$ \\
\hline $\begin{array}{l}\text { Control of } \\
\text { simulation start } \\
\text { (token creation) } \\
\end{array}$ & $\begin{array}{l}\text { supported (fixed, } \\
\text { stochastic, calendar) }\end{array}$ & $\begin{array}{c}\text { Not supported (fixed } \\
\text { not changeable) }\end{array}$ & not supported \\
\hline
\end{tabular}

Table 1: Comparison capabilities in batch processing activities simulation 


\subsection{Comparison of batch processing simulation capabilities of IBM, BizAgi and TD ABC}

The comparison of batch processing simulation capabilities was made by testing the IBM WebSphere Business Process Modeler Advance version 7.0.0.4.1 (Latest version of $29^{\text {th }}$ September 2011 [13]), BizAgi Modeler version. 3.1 (latest version of $22^{\text {th }}$ September 2016 [4]) and TDABC model, implemented in Microsoft Excel.

Table 1 shows the analysis results in a way that relevant criteria for comparison are listed and capabilities of tools are evaluated.

\section{Conclusion}

Although, most BPM tools support process simulations, there are some issues regarding their simulation capabilities that can limit or obstruct their usage. BPM tools that support BPMN 2.0 standard and have embedded simulation features, differ in the capabilities of running process simulations. The main relevant difference shown in this paper is referring to handling batch processing activities with complex properties. These properties are linked to a number of business item instances input and output that can vary depending on complex events or gateways prior to the process sequence. Variable business item instances input are hard to set in most BPM tools, especially because of their influence on the execution of the activity, which the business item activates. Furthermore, depending on activity's input settings there are various business scenarios of executing the activity: some activities are executed multiple times for multiple inputs, some activities are executed only once for multiple instances and some activities are executed multiple times for one input instance. These various scenarios also impact the duration of batch processing activity in the process simulation and need to be managed.

In order to overcome these batch processing challenges, contemporary BPM tools with BPMN 2.0 support, need to implement options for handling these various business process simulation scenarios. As a temporary solution, the time driven activity based on the method model (TD ABC model) and the manual simulation could help to overcome these issues, as shown in previous sections. Comparison of BPM tools simulation capabilities reveals significant limitations of prominent contemporary BPM tools with the process simulation features, as assessed and discussed in the final chapter, showing advantages and disadvantages.

Further research, should focus on suggesting upgrades of BPM tools for overcoming the described issues for most common batch processing activities, regarding their proper handling in such a way that they will be useful, in accordance with BPMMN 2.0, without sacrificing business process logic while giving correct results for the abovementioned examples.

\section{References}

[1] Aalst, W. M. P. (2013). Business Process Simulation Survival Guide. https://pdfs.semantic scholar.org/07c9/b55ebf0fe9e446bd0af4f7480ff00f3019ec.pdf [Accessed 21/12/17].

[2] Alexander, C. W. (2006). Discrete Event Simulation for Batch Processing. Proceedings of the 2006 Winter Simulation Conference, 1929-1934. 
[3] ARIS Community. (2018). Business Process Simulation. http://www.ariscommunity.com/ business-process-simulation [Accessed 10/01/18].

[4] BizAgi. (2018). BizAgi Process Modeler. http://www.bizagi.com/en/products/bpmsuite/modeler [Accessed 10/01/18].

[5] Bosilj Vukšić, V., Hernaus, T. and Kovačić, A. (2008). Upravljanje poslovnim procesima: organizacijski i informacijski pristup. Zagreb: Školska knjiga.

[6] Damij, N., Boškoski, P., Bohanec, M. and Mileva Boshkoska, B. (2016). Ranking of Business Process Simulation Software Tools with DEX/QQ Hierarchical Decision Model. PLoS ONE, 11(2), 1-16. https://doi.org/10.1371/journal.pone.0148391 [Accessed 10/01/18].

[7] Feraitas, A. P. and Pereira, J. L. (2015). Process Simulation Support in BPM Tools: The Case of BPMN, Proceedings of 2100 Projects Association Joint Conferences, X(20XX).

[8] Gartner. (2010). Magic Quadrant for Business Process Analysis Tools. https://mqit.wordpress.com/2011/02/16/gartner-magic-quadrant-for-business-processmanagement-suites/ [Accessed 10/01/18].

[9] Gartner. (2014). IBM Named a Leader in the 2014 Gartner Magic Quadrant for iBPMS. http://www.safira.pt/pt/en/pages/278/gartner-magic-quadrant-ibpms-march-2014-ibmnamed-a-leader.html [Accessed 10/01/18].

[10] Gartner. (2016). Magic Quadrant for Intelligent Business Process Management Suites. http://www.integra-co.com/sites/default/files/Bizagi\%20on\%20Gartner\%20Quadrant\%20 -\%20Reprint.pdf [Accessed 10/01/18].

[11] Greasley, A. (2003). Using business-process simulation within a business-process reengineering approach. Business Process Management Journal, 9(4), 408-420.

[12] Hoyer, V. (2008). Modeling Collaborative e-Business Processes in SME environments. Journal of Information Science and Technology, 5, 46-59.

[13] IBM. (2018). IBM WebSphere Business Modeler. https://www.ibm.com/developerworks/ downloads/ws/wbimod/ [Accessed 10/01/18].

[14] IBM Knowledge Center. (2018). Glossary v8.0.0. Business item. https://www.ibm.com/ support/knowledgecenter/SSWLGF_8.0.0/com.ibm.websphere.help.glossary.doc/topics/glo ssary.html [Accessed 10/01/18].

[15] iGrafx. (2013). iGrafx receives Positive Rating in Gartner Market Scope for Enterprise Process Analysis. http://www.igrafx.com/assets/pdf/iGrafx-GartnerMarketScope12022013.pdf [Accessed 10/01/18].

[16] iGrafx. (2018). iGrafx PROCESS - Easily Perform What-If Analysis for Innovation and Continuous Improvement. http://www.igrafx.com/gl/products/process-modeling-analysis/ process [Accessed 10/01/18].

[17] Kaplan, R. S. and Anderson, S. R. (2007). Time-Driven Activity-Based Costing: A Simpler and More Powerful Path to Higher Profits. Harvard Business School Press.

[18] Liu, J. and Hu, J. (2007). Dynamic batch processing in workflows: Model and implementation. Journal Future Generation Computer Systems, 23, 338-347.

[19] Melao, N. and Pidd, M. (2003). Use of Business Process Simulation: A Survey of Practitioners. The Journal of the Operational Research Society, 54(1), 2-10.

[20] OMG. (2018). Business Process Model and Notation BPMN 2.0. http://www.bpmn.org/ [Accessed 10/01/18]. 
[21] Peacock, E. and Tanniru, M. (2005). Activity-based justification of IT investments. Information \& Management, 42, 415-424.

[22] Pihir, I., Žajdela Hrustek, N. and Dušak, V. (2010). Survey of Simulation Capabilities of the IBM WebSphere Business Modeler Business Process Modeling Tool on the Example of Processing a Loan Application. Proceedings of the ITI 2010 32nd International Conference on Information Technology Interfaces, Cavtat, Croatia, 645-650.

[23] Pufahl, L. and Weske, M. (2013). Batch Activities in Process Modeling and Execution. Lecture Notes in Computer Science, 8274, 283-297.

[24] Seila, A. F., Čerić, V. and Tadikamalla, P. (2003). Applied Simulation Modeling. London:Thompson - Brooks/Cole.

[25] Silver, B. (2011). BPMN Method \& Style. 2nd edition. Cody-Cassidy Press.

[26] Software AG. (2016). Simulation - Analyse and improve processes.

http://www1.softwareag.com/corporate/images/SAG_ARIS_Simulation_FS_Feb16_web _tcm16-78560.pdf [Accessed 10/01/18].

[27] Weske, M. (2012). Business Process Management - Concepts, Languages, Architectures. 2nd edition. Springer.

[28] Wikipedia. (2018). Batch Processing. https://en.wikipedia.org/wiki/Batch_processing [Accessed 10/01/18].

[29] Wynn, M. T., Dumas, M., Fidge, C. J., ter Hofstede A. H. M. and van der Aalst, W. M. P. (2008). Business Process Simulation for Operational Decision Support. In: ter Hofstede A., Benatallah B., Paik HY. (eds) Business Process Management Workshops. BPM 2007. Lecture Notes in Computer Science, 4928, 66-77, Berlin, Heidelberg: Springer.

[30] Zarei, M., Zarei, B. and Ghapanchi, A. H. (2017). Lessons learnt from process improvement in a non-profit organisation. International Journal of Business Excellence, 11(3), 277-300. 